\title{
Perceptual content and the content of mental imagery
}

\section{Bence Nanay}

\section{Philosophical Studies}

An International Journal for Philosophy in the Analytic Tradition

\section{ISSN 0031-8116}

Volume 172

Number 7

Philos Stud (2015) 172:1723-1736

DOI 10.1007/s11098-014-0392-y

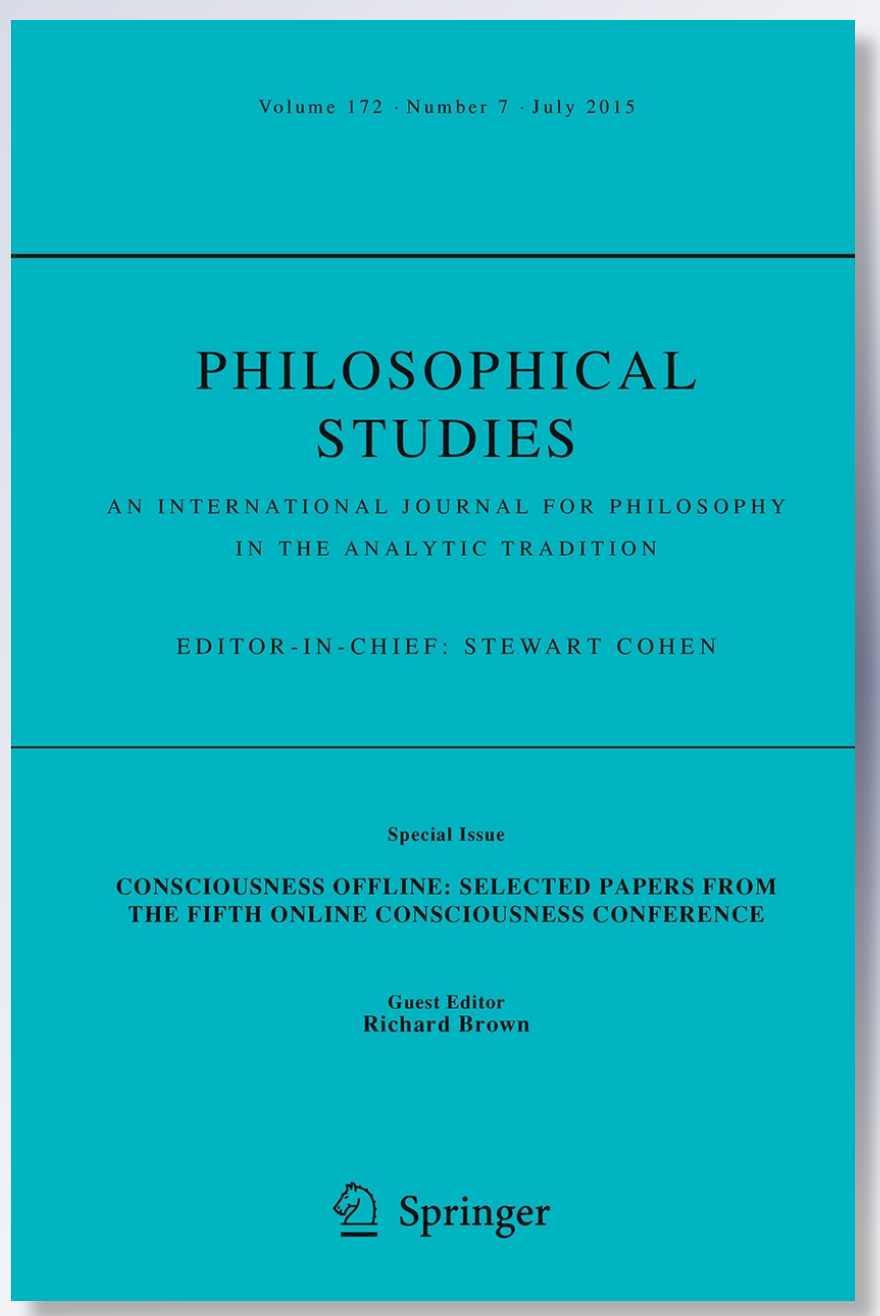


Your article is protected by copyright and all rights are held exclusively by Springer Science +Business Media Dordrecht. This e-offprint is for personal use only and shall not be selfarchived in electronic repositories. If you wish to self-archive your article, please use the accepted manuscript version for posting on your own website. You may further deposit the accepted manuscript version in any repository, provided it is only made publicly available 12 months after official publication or later and provided acknowledgement is given to the original source of publication and a link is inserted to the published article on Springer's website. The link must be accompanied by the following text: "The final publication is available at link.springer.com". 


\title{
Perceptual content and the content of mental imagery
}

\author{
Bence Nanay
}

Published online: 5 October 2014

(C) Springer Science+Business Media Dordrecht 2014

\begin{abstract}
The aim of this paper is to argue that the phenomenal similarity between perceiving and visualizing can be explained by the similarity between the structure of the content of these two different mental states. And this puts important constraints on how we should think about perceptual content and the content of mental imagery.
\end{abstract}

Keywords Perceptual content · Mental imagery · Attention · Determinacy · Determinable/determinate properties · Dependency Thesis

Red, as seen by the mind and not the eye, exercises at once a definite and an indefinite impression on the soul. (Wassily Kandinsky, 1910)

\section{Introduction}

Seeing and visualizing have very similar phenomenal character. If I visualize a red apple and if I see one, the phenomenal character of my experience will be very similar. Question: how can we explain this similarity?

This phenomenal similarity between seeing and visualizing seems intuitively salient, but for those (like myself) who mistrust intuitive evidence, there is empirical evidence for this similarity. In the Perky experiments, subjects looking at a white wall were asked to visualize objects while keeping their eyes open. Unbeknownst to them, barely visible images of the visualized objects were projected on the wall. The surprising finding is that the subjects took themselves to be visualizing the objects-while in fact they were

\section{B. Nanay}

Centre for Philosophical Psychology, University of Antwerp, Antwerp, Belgium

B. Nanay $(\square)$

Peterhouse, University of Cambridge, Cambridge, UK

e-mail: bn206@cam.ac.uk 
perceiving them (Perky 1910; Segal 1972; Segal and Nathan 1964). The standard interpretation of this experiment is that if perceiving and visualizing could be confused under these circumstances, then they must be phenomenally very similar (but see Hopkins 2012's criticism and Nanay 2012b's response).

I have been emphasizing the phenomenal similarity between seeing and visualizing, but it should be clear that these two mental episodes also differ in important ways. Although under some special circumstances, like the one just mentioned, we can confuse the two, we normally don't do so. Any account of perception or of mental imagery needs to be able to explain both the similarities and differences between the phenomenal character of perception and mental imagery. This is what I aim to do in this paper.

The plan is the following: After clarifying what is meant by mental imagery (Sect. 2), I analyze the two main theories for explaining the phenomenal similarity between perception and mental imagery, the Similar Content View and the Dependency Thesis (Sect. 3) and then proceed to give a version of the Similar Content View (Sects. 4 and 5) that is more explanatorily powerful and therefore preferable both to other versions of the Similar Content View and to the Dependency Thesis (Sect. 6).

\section{Mental imagery}

Here is a relatively general characterization of mental imagery:

Mental imagery refers to all those quasi-sensory or quasi-perceptual experiences [...] which exist for us in the absence of those stimulus conditions that are known to produce their genuine sensory or perceptual counterparts, and which may be expected to have different consequences from their sensory or perceptual counterparts (Richardson 1969, pp. 2-3).

It is easier to explain mental imagery in the visual sense modality, which is the one I will mainly be focusing on. A paradigmatic case of visual imagery would be closing one's eyes and imagining seeing an apple 'in the mind's eye' (see Kosslyn 1980; Kosslyn et al. 1995, 2006; see also Ryle 1949, chapter 8.6; Kleiman 1978, Matthews 1969, Shorter 1952 Currie and Ravenscroft 2002). The equivalent of visual imagery in other sense modalities would be auditory or tactile or olfactory imagery. I will use the term 'mental imagery' to refer to all of these.

It is important to point out that visual imagery does not necessarily imply visualizing, that is, an active, intended act. Having mental imagery can be passive and is not necessarily intended. Visualizing is one way of having mental imagery, but it is not the only way. We can have mental imagery even if we are not trying to visualize anything - when, for example, we are having involuntary flashbacks to some scene that we have seen earlier. This is especially clear if we shift our attention to the auditory sense modality and consider earworms: tunes that pop into our heads and that we keep on having auditory imagery of, even though we do not want to.

Another kind of involuntary mental imagery is the following: It has been argued (Nanay 2010b) that amodal perception (or at least most instances of amodal perception, see Briscoe 2011), that is, the representation of unseen parts of objects 
we see, is also a sub-category of mental imagery, where, again, we attribute properties quasi-perceptually to a part of the perceived object that is not visible (see also Page et al. 2011). Further, if mental imagery is a necessary feature of episodic memory (Byrne et al. 2007, see also Berryhill et al. 2007's overview), then it is also involuntary inasmuch as episodic memory can also be involuntary.

Having mental imagery of an apple should be differentiated from imagining that there is an apple in the kitchen, an imagining episode, which amounts to having a propositional attitude. It is a complicated question whether and how imagining that there is an apple in the kitchen is different from supposing that there is an apple in the kitchen, but what matters for us is that both of them are different from having mental imagery of an apple. Both 'imagining that' and 'supposing that' are propositional attitudes, whereas having mental imagery, whatever it may be, is not (see Nanay 2009, 2010b; Van Leeuwen 2011; Schellenberg 2013).

\section{The Dependency Thesis versus the Similar Content View}

There are two general approaches to explaining the phenomenal similarity between perception and mental imagery: the 'Dependency Thesis' and the 'Similar Content View' (I borrow the labels from Martin 2002; Noordhof 2002, p. 439, respectively).

According to the Similar Content View, the phenomenal similarity between perception and mental imagery is explained by the similarity between the content of these two mental states (Ishiguro 1967; cf. Kind 2001; Currie 1995, pp. 36-37, Currie and Ravenscroft 2002, p. 27; Noordhof 2002). The main alternative to this view is the suggestion that visualizing $\mathrm{x}$ consists of representing the experience of $\mathrm{x}$. The basic idea is that it is not the similarity between the content of seeing and visualizing that explains why seeing and visualizing are phenomenally similar. Rather, by representing it, mental imagery inherits the phenomenal properties of experiencing x (Martin 2002, p. 406; Smith 2006, pp. 53-54). This is the so-called Dependency Thesis (Peacocke 1985; Martin 2002, see also Noordhof 2002 for analysis).

The first thing to note is that it is not at all obvious why the Dependency Thesis would explain the phenomenal similarity between perception and mental imagery. After all, it posits that mental imagery and perception has radically different content: 'experiencing $\mathrm{x}$ ' and ' $\mathrm{x}$ ', respectively. How could we have qualitatively very similar experiences if the contents of our mental states are radically different? (Currie and Ravenscroft 2002, p. 28).

But this line of criticism ignores what Martin calls the 'transparency' of imagined experiences. He says:

[...] I assume at this stage that Dependency commits one to the claim that in imagining some scene one thereby imagines an experience of the scene-it is no part of Dependency to deny that one imagines the scene when one imagines an experience of the scene (Martin 2002, p. 404).

Thus, Martin's strategy is to say that by imagining an experience of a chair, we do imagine a chair. Thus, the content of our mental imagery is the experience of a chair 
but it is also the chair itself. ${ }^{1}$ Both the content of mental imagery and that of perceiving include the chair itself.

I will not argue against the Dependency Thesis here (but see Noordhof 2002; Currie and Ravenscroft 2002; Gregory 2010) — my aim is to give the most plausible version of the Similar Content View. But I will return to the Dependency Thesis in the last section and compare its explanatory force with my version of the Similar Content View.

So, let's return to the Similar Content View. Again, the view is that the phenomenal similarity between perception and mental imagery is explained by the similarity between the content of these two mental states. The plausibility of the Similar Content View clearly depends on the way we think about perceptual content. Perceptual content is a semi-technical term and depending on how we conceive of perceptual content, we end up with very different versions of the Similar Content View. This means that the Similar Content View needs to be supplemented with an account of the nature of perceptual content and of the content of mental imagery.

Here is one way of thinking about perceptual content that does not seem to be particularly promising when it comes to fleshing out the Similar Content View. If we equate perceptual content with the object the perceptual state is about, then the Similar Content View will amount to saying that visualizing a green chair and seeing one have similar phenomenal character, because the green chair that I see is similar to the green chair that I visualize.

The problem is that this view does not seem to have the resources to explain in what sense the two kinds of contents are similar. The green chair that I visualize may not exist, whereas the one I see surely does. In short, under this conception of perceptual content, the content of perceptual states and of mental imagery are very different indeed: an actual token object versus a potentially nonexistent object.

As we have seen, the plausibility of the Similar Content View very much depends on what they take to be the content of mental imagery and perceptual content. And most contemporary proponents of this approach take both perceptual content and the content of mental imagery to be propositional. Gregory Currie, for example, who gives probably the most thoroughly worked out contemporary version of the Similar Content View proposes two different accounts of the content of mental imagery in different works. In 1995, he says that "the content of visual imagery is always of the form,'That I am seeing such-and-such'” (Currie 1995, pp. 36-37), but 7 years later, in Currie and Ravenscroft (2002), he seems to endorse a very different account of content when he says that "if I have a visual image of a mountain, then the content of my imagining [...] is the mountain or, if we want to make all contents propositional, there being a mountain somewhere" (Currie and Ravenscroft 2002, p. 27). Both of these accounts take perceptual content and the content of mental imagery to be propositional. But if we think of perceptual content and the content of mental imagery this way, then it becomes less clear how the similarity of content

\footnotetext{
1 See also Smith (2006, footnote 18) "We imagine a tiger by imagining seeing it. It does not follow that because we are imagining an experience we fail to imagine the object of the experience. Given this, there is every reason to think that seeing an $F$ and imagining seeing an $F$ will be phenomenologically similar".
} 
would explain the similarity of phenomenology. There are many propositional attitudes (beliefs, hopes, desires, etc.) that could share the same propositional content with perception and they do not seem to share the same phenomenology. Maybe more can be said about the nature of these propositional contents, but neither Currie not other contemporary proponents of the Similar Content View provide any further specification.

The aim of the present paper is to work out the most plausible version of the Similar Content View. In order to do so, I need to give a precise account of what perceptual content is, of what the content of mental imagery is and of what constitutes the similarity between the two.

\section{Perceptual content}

Here is my version of the Similar Content View. Consider the following, very simple, and not particularly controversial, way of thinking about perceptual content (Nanay 2010a). Our perceptual apparatus attributes various properties to various parts of the perceived scene, where I take the perceived scene to be spatially (and not propositionally) organized, in the way Peacocke's scenario content is (Peacocke 1992-see also Crane 2009; Burge 2010 for other accounts of non-propositional perceptual content). Perceptual content is constituted by the properties that are perceptually attributed to the perceived scene.

In order to maintain the generality of this account of perceptual content, I will say nothing about whether these properties are tropes or universals (Nanay 2012c) or whether this content is structured in a Fregean or Russellian manner. The question I want to explore here is what degree of determinacy these perceptually attributed properties have.

Being red is determinate of being colored, but determinable of being scarlet (Johnston 1921; Funkhouser 2006). There are many ways of being red and being scarlet is one of these: for something to be scarlet is for it to be red, in a specific way. If something is red, it also has to be of a certain specific shade of red: there is no such thing as being red simpliciter.

The determinable-determinate relation is a relative one: the same property, for example, of being red, can be the determinate of the determinable being colored, but the determinable of the determinate being scarlet. Thus, the determinabledeterminate relation gives us hierarchical ordering of properties in a given property-space. Properties with no further determinates, if there are any, are known as super-determinates.

Some of the properties we perceptually attribute to the perceived scene are determinates or even super-determinates. Some others, on the other hand, are determinable properties. We know that our peripheral vision is only capable of attributing extremely determinable properties. But even some of the properties we perceptually attribute to the objects that are in our fovea can be determinable.

It has been argued that if we accept this way of thinking about content, then perceptual attention should be thought of as a necessary feature of perceptual content (Nanay 2010a, 2011c). More precisely, attention makes (or attempts to 
make) the attended property more determinate (see also Yeshurun and Carasco 1998 for empirical evidence and Stazicker 2011 for a philosophical summary). If I am attending to the color of my office telephone, I attribute very determinate (arguably super-determinate) properties to it. If, as it is more often the case, I am not attending to the color of my office telephone, I attribute only determinable properties to it (of, say, being light-colored or maybe just being colored). In short, attention makes (or attempts to make) the perceived property more determinate.

An important clarification: a shift of visual attention is not to be confused with eye movement. It is possible to shift one's visual attention without any accompanying eye movement-this is a widely researched phenomenon of the 'covert shift of attention' (Posner 1980, 1984; Posner et al. 1984; see also Findlay and Gilchrist 2003). But more often the shift of attention is accompanied by eye movement, which, following the literature, I call an 'overt shift of attention'. Both in the case of overt and of covert shifts of attention, the determinacy of the attended property changes. This distinction will play an important role in the last section.

More clarifications: First, what are these perceptually attributed properties the sum total of which would constitute perceptual content? More simply, what kinds of properties are the ones that we perceive objects as having - and not only believe, non-perceptually, that the object has them? There is a grand debate in philosophy of perception about the range of perceptually represented properties. Shape, size, color and spatial location are prime candidates, but there may be more. A couple of quick examples: it has been argued that we perceive objects as trees and tables (Siegel 2006), as being causally efficacious (Siegel 2005, 2009), as edible, climbable or Q-able in general (Nanay 2011a, 2012a), as agents (Scholl and Tremoullet 2000), as having some kind of normative character or value (Kelly 2010; Matthen 2010), as having dispositional properties (Nanay 2011b), as having action-properties (Nanay 2012d, 2013), as having moral value (Kriegel 2007) and as affording certain actions (for very different versions of this claim, see Gibson 1966, 1979; Bach 1978, esp. p. 368; Jeannerod 1988, 1994, esp. Sect. 5, 1997; Jacob and Jeannerod 2003, esp. pp. 202-204; Humphreys and Riddoch 2001; Riddoch et al. 1998, esp. p. 678). I want to remain neutral here about the range of properties that are perceptually represented. Whichever properties are the ones that we perceive objects as having, perceptual content is the sum total of properties of this kind.

Second, what is meant by the 'perceived scene' these properties are perceptually attributed to? This is another severely debated question in philosophy of perception: what are the 'sensory individuals' that these properties are attributed to? Are they ordinary objects (Pylyshyn 2007; Cohen 2004; Matthen 2004)? Are they spatiotemporal regions (Clark 2000, 2004)? Are they different depending on which sense modality we consider (Batty 2010; Lycan 2000; O'Callaghan 2007, Clark 2011, Nanay 2013)? Again, my account is compatible with any of these answers.

\section{The content of mental imagery}

I outlined a simple, and not particularly controversial, account of perceptual content in the last section. But what is the content of mental imagery? My answer is that the content of mental imagery is exactly the same as the content of perceptual states. 
More precisely, our imagery attributes various properties to various parts of the imagined scene. The content of imagery is the sum total of the properties attributed to the imagined scene. Some of these properties are determinates or even superdeterminates. Some others are determinables. Attention makes (or tries to make) the attended property more determinate.

What is then the difference between perceptual content and the content of mental imagery? The only difference concerns where the extra determinacy comes from. As we have seen, both in the case of perceptual content and in the case of mental imagery, attention makes the attended property more determinate. This increase in determinacy in the case of perception comes from the sensory stimulation: if I am attending to the color of the curtain in the top left window of the building in front of me, this color will be more determinate than it was when I was not attending to it. This difference in determinacy is provided by the world itself-I can just look: the exact shade of the curtain's color is there in front of me to be seen.

In the case of mental imagery, this difference in determinacy, in contrast, is not provided by the sensory stimulation, for the simple reason that there is no sensory stimulation that would correspond to what I visualize: if I visualize the house I grew up in and you ask me to tell what exact color the curtain in the top left window was, I can shift my attention to that color and I can even visualize the exact color of the curtain. However, this increase in determinacy is not provided by the sensory stimulation (as I don't have any), but by my memories (or what I take to be my memories) or my beliefs or expectations. ${ }^{2}$

Let's consider another example where the increase in determinacy is not provided by memories (or by what I take to be my memories), but my expectations: suppose that I order a steak in a restaurant and I have a mental imagery of the meal the waiter is about to bring me. I can shift my attention around here as well-I can attend to the texture of the meat, for example. This, again, would entail an increase in the determinacy of this imagined texture-property, but this increase is not provided by memories, but by my expectations-in this case, expectations based on my belief about how I ordered the steak to be done.

In the steak example, my expectation is based on my belief about what I ordered. But expectations don't have to be based on rationally justified beliefs. If I imagine what my grandchild may look like, and attend to his/her nose, the increase in determinacy is unlikely to come from anything rationally justified. It may come from my expectations nonetheless (most likely from completely unjustified expectations).

Clarifications: First, my account is not committed to there being a clear-cut distinction between perception and mental imagery. In the modified Perky

\footnotetext{
2 There are interesting implications of this parallel between the exercise of perceptual attention and of attention in the case of mental imagery. Perceptual attention is often described as some kind of selection: selection from informational overload, selection for action etc. This way of talking about attention seems fitting for perceptual attention. But it is much more difficult to make sense of the selection metaphor in the case of attending to mental imagery as it is not at all clear what is supposed to be selected (given that there is no sensory stimulation). I can't pursue the implications of this asymmetry here, but one possible way of addressing it would be to give up on the selection metaphor of attention altogether (even in the case of perceptual attention).
} 
experiments (Segal 1972), the picture projected on the wall and the image the subjects were asked to visualize were different, resulting in an interesting juxtaposition of the two images. In this case, it would be difficult to tell whether the subject perceives or exercises mental imagery—she does both (see Trehub 1991 for some further experiments involving mixed perception/mental imagery). The fact that according to my account the structure of the content of these two mental episodes is the same makes it easy to account for mixed cases like this (other, somewhat different examples of mixed perception/mental imagery are given in Martin 2002, p. 410 and in Van Leeuwen 2011). The increase in determinacy is provided by both the sensory stimulation and our memories/beliefs in these cases.

Second, my claim is not that attention makes the attended property more determinate, but that it makes or tries to make the attended property more determinate. It does not always succeed. And this is so both in the case of perceiving and in the case of visualizing. When I attend to something that I see in the periphery of my visual field and I cannot move my eyes, the shift of my attention tries to make the properties of this object more determinate but because this object is, and continues to be, in the periphery of my visual field, I will not succeed. The same goes for mental imagery. If I am asked to visualize my first credit card and attend to its color, I may just simply not remember and in this case, although attention tries to make the attributed property more determinate, it may not succeed.

In short, the difference between perceptual content and the content of mental imagery is not a difference between the structure of these contents-they have the very same structure. The difference is between the dynamics of how the represented properties, and, importantly, the determinacy of the represented properties change in response to the allocation of attention. The difference is not between what perceptual content and the content of mental imagery are, but between the way they change.

It is important to emphasize that the claim is not that the properties attributed in the content of mental imagery are less determinate than the ones that are attributed in perceptual content. The properties that constitute the content of mental imagery can be very determinate indeed-and most of the properties that constitute perceptual content are not particularly determinate (see Dennett 1996). The claim is that the difference between the content of these two mental states is the way this determinacy comes about.

How can this version of the Similar Content View explain the phenomenal similarity between perception and mental imagery? We have seen that if we accept other contemporary versions of the Similar Content View, ones that construe content as propositional, then we do not get a straightforward account of why the similarity of content would explain the similarity of phenomenal character (as some other propositional attitudes with the same proposition have very different phenomenology).

And here my version of the Similar Content View is in a better position - because of the emphasis on attention. Attention, as the famous 'inattentional blindness' phenomenon shows, can dramatically change what we experience (Simons and Chabris 1999; Mack and Rock 1998). This phenomenon has been known for a long time. Rezső Bálint, a Hungarian physician after whom Balint-syndrome was named wrote in 1909: 
It is a well-known phenomenon that we do not notice anything happening in our surroundings while being absorbed in the inspection of something; focusing our attention on a certain object may happen to such an extent that we cannot perceive other objects placed in the peripheral parts of our visual field, although the light rays they emit arrive completely at the visual sphere of the cerebral cortex (Bálint 1909/1995)

More recently, various experiments about inattentional blindness have demonstrated that we fail to experience those features of our surroundings that we are not paying attention to (Mack and Rock 1998). Probably the most famous inattentional blindness experiment is the following (Simons and Chabris 1999). We are shown a short video-clip of two teams of three, dressed in white and black, passing a ball around. We are asked to count how many times the white team passes the ball around. On first viewing, most of the observers come up with an answer to this not very interesting question. On second viewing, however, when there is no counting task to be completed, they notice that a man dressed in gorilla costume walks right in the middle of the passing game, makes funny gestures and then leaves. The gorilla spends nine seconds in the frame and most viewers do not notice it when attending to the passing of the ball.

Without going into the details of the debates concerning the exact philosophical implications of these findings (Wolfe 1999; Prinz 2010; Nanay 2010a), what these empirical and everyday phenomena show is that attention can make a huge difference in what we experience (see also Hill 1991, pp. 123-126; Block 1995, esp. p. 231). But then it should not come as a surprise that similar allocation of attention in the case of perception and mental imagery can explain the similarity between the phenomenology of perception and mental imagery. My version of the Similar Content View has a more straightforward way of explaining the phenomenal similarity between perception and mental imagery than other versions of the Similar Content View.

In the last section, I will argue that my version of the Similar Content View is also preferable to the Dependency Thesis because it is more explanatorily powerful.

\section{The explanatory power of the Similar Content View}

I want to argue that the version of the Similar Content View I outlined in the previous sections is to be preferred not only to other versions of the Similar Content View, but also to the Dependency Thesis. The reason for this is that my version of the Similar Content View explains a number of puzzling features of mental imagery that other accounts are not capable of explaining.

What are these puzzling features? The first one is the following (I will focus on the visual sense modality for ease of exposure, but we have very similar phenomena in the olfactory sense modality, see Bensafi et al. 2003): our eye movement during visual imagery re-enacts that of the perception of the same visual scene. When we visualize a scene, our spontaneous eye movements reflect the content of the visual scene (Brandt and Stark 1997; Laeng and Teodorescu 2002; Mast and Kosslyn 
2002; Spivey and Geng 2001; Johansson et al. 2006; Altmann 2004, see also Laeng et al. 2014 for a good summary). When we perceive a pattern in a grid, our eye movements are isomorphic to our eye movements when we visualize the same pattern.

How could this be possible if the Dependency Thesis is correct? If it is true that when visualizing $\mathrm{x}$, what we imagine is the experience of $\mathrm{x}$, then how could visualizing involve spontaneous eye movement, which is a feature of experiencing $\mathrm{x}$ ? According to the Dependency Thesis, visualizing is not something structurally similar to experiencing, but the representation of experiencing. Eye movement is a feature of experiences, not of the representations thereof. Thus, the Dependency Thesis does not predict that our eye movements during visual imagery are similar to those during vision.

Let us go through this argument more slowly. First, eye movement is not an optional feature of visual perception. If the sensory stimulation on our retina does not change (if we have what is called a 'stabilized retinal image'), then we cease to see anything whatsoever (see Heckenmueller 1965 for a classic overview). In general, it is an important feature of visual perception that if the retinal image remains the same even for a short time, we cease to have any visual experience. We can have visual experiences only if our retinal image changes continuouslynormally as a result of the micro-saccades (or micro-movements) of the eye (see Findlay and Gilchrist 2003 for an excellent summary). If this is true, however, then one cannot be in a perceptual state if one's retinal image is stabilized. Thus, eye movement is a necessary feature of experiencing anything visually.

Second, according to the Dependency Thesis, visualizing x consists of imagining (that is, representing) experiencing $x$. Experiencing $x$, as we have seen, must involve eye movement. However, according to the Dependency Thesis, visualizing $\mathrm{x}$ consists of imagining (that is, representing) experiencing $\mathrm{x}$. But representing is not something that would involve specific eye movements. In fact, most often, it doesn't. It is the content of this representation, that is, the experience of $x$ that involves eye movements. Why is it then, that the vehicle of this representation requires identical eye movements to the ones the content of this representation requires?

All this argument shows is that the Dependency Thesis does not predict that visual imagery involves eye movements that are isomorphic to our eye movements during perception. The proponents of this approach may appeal to some, independent, explanation for why visual imagery involves such eye movements, but this explanation is not provided by the Dependency Thesis itself.

The version of the Similar Content View I outlined above, in contrast, provides an explanation for the isomorphic eye movements in the case of vision and visual imagery. As we have seen, shift of visual attention can happen in the absence of eye movements, but it is typically accompanied by corresponding eye movement. And as our attention moves around the visualized object in the same way as it moves around the perceived object, we should expect that our eye movements will also be similar.

This explanatory scheme is supported by another important body of empirical findings about visualization. If subjects are asked not to move their eyes during 
visualizing, they have difficulties imagining the scene and if they can do so, they attribute only very rudimentary features to the imagined object (Laeng and Teodorescu 2002; see also Mast and Kosslyn 2002). And this is exactly what my account predicts: if our eyes are fixated and, as a result, our attention is not as free to move around as it would be otherwise, then we should expect that as a result of the lack of shifts of attention, it will be difficult to increase the determinacy of the properties imagery attributes to the visualized scene. Hence, we end up with an impoverished visualized image. To sum up, my version of the Similar Content View explains the peculiarities of our eye movements during imagery, whereas the Dependency Thesis does not.

It is important to note that both the findings about the isomorphic eye movements in vision and visual imagery and the findings about the difficulties to visualize while fixating are hard to explain even if we accept those versions of the Similar Content View that take perceptual content and the content of mental imagery to be propositional. The similarity of propositions would not in itself explain why our eye movements while perceiving and while visualizing would be similar. It doesn't explain why fixation would diminish our capacity to visualize either. While it is possible to supplement these propositional versions of the Similar Content View with an explanation of these phenomena, they do not themselves provide such explanations. My version does.

My version of the Similar Content View also explains yet another puzzling fact about mental imagery, namely, that it is relatively old phylogenetically: we have evidence that even pigeons are capable of mental imagery (Rilling and Neiworth 1987; Neiworth 1992; see also Oakley 1985 for a summary). This fact seems to flatly contradict the Dependency Thesis as it would imply that pigeons are capable of representing a mental state, namely, their experiences. But the cognitive ethology literature strongly disagrees. There is an important debate about whether chimpanzees are capable of this (see, e.g. Call and Tomasello 2008; Tomasello et al. 2003; Penn and Povinelli 2007), but even if they do, primatologists agree that not even monkeys have this ability, let alone pigeons (see Cheeny and Seyfarth 1990 for a summary).

If we accept the version of the Similar Content View I outlined above, the findings about the mental imagery of pigeons will not sound surprising at all. Pigeons can see the world: they can attribute properties visually to the perceived scene and the determinacy of these properties change depending on their attention. As the content of mental imagery is exactly the same (again, with the exception that the increase in determinacy is provided by memory and not by sensory stimulation), we have no reason to doubt that they may be capable of mental imagery (especially as pigeons have relatively developed memory).

In short, the explanatory power of the version of the Similar Content View I defended here is more significant than that of the Dependency Thesis. We have good reason to accept it.

Acknowledgments This work was supported by the EU FP7 CIG grant PCIG09-GA-2011-293818 and the FWO Odysseus grant G.0020.12N. I presented this paper at the Fourth Online Consciousness 
Conference and I am grateful for the comments I received there. I am also grateful for comments by Neil Van Leeuwen, Jake Berger and an anonymous referee for this Journal on an earlier draft.

\section{References}

Altmann, G. T. M. (2004). Language-mediated eye movements in the absence of a visual world: The 'blank screen paradigm'. Cognition, 93, 79-87.

Bach, K. (1978). A representational theory of action. Philosophical Studies, 34, 361-379.

Bálint, R. (1909/1995). Seelenlahmung des 'Schauens', optische Ataxie, raumliche Storung der Aufmerksamkeit. Monatsschrift fur Psychiatrie und Neurologie, 25, 51-81. (English translation: Cognitive Neuropsychology 12, 265-281).

Batty, C. (2010). Scents and sensibilia. American Philosophical Quarterly, 47, 103-118.

Bensafi, M., et al. (2003). Olfactomotor activity during imagery mimics that during perception. Nature Neuroscience, 6, 1142-1144.

Berryhill, M. E., Phuong, L., Picasso, L., Cabeza, R., \& Olson, I. R. (2007). Parietal lobe and episodic memory: Bilateral damage causes impaired free recall of autobiographical memory. Journal of Neuroscience, 27, 14415-14423.

Block, N. (1995). A confusion about consciousness. Behavioral and Brain Sciences, 18, 227-247.

Brandt, S. A., \& Stark, L. W. (1997). Spontaneous eye movements during visual imagery reflect the content of the visual scene. Journal of Cognitive Neuroscience, 9, 27-38.

Briscoe, R. (2011). Mental imagery and the varieties of amodal perception. Pacific Philosophical Quarterly, 92, 153-173.

Burge, T. (2010). The origins of objectivity. Oxford: Clarendon.

Byrne, P., Becker, S., \& Burgess, N. (2007). Remembering the past and imagining the future: A neural model of spatial memory and imagery. Psychological Review, 114, 340-375.

Call, J., \& Tomasello, M. (2008). Does the chimpanzee have a theory of mind? 30 years later. Trends in Cognitive Sciences, 12, 187-192.

Cheeny, D. L., \& Seyfarth, R. M. (1990). How monkeys see the world. Chicago: University of Chicago Press.

Clark, A. (2000). A theory of sentience. Oxford: Clarendon Press.

Clark, A. (2004). Sensing, objects, and awareness: Reply to commentators. Philosophical Psychology, 17, $563-589$.

Clark, A. (2011). Vicissitudes of non-visual objects. Philosophical Studies, 153, 175-181.

Cohen, J. (2004). Objects, places, and perception. Philosophical Psychology, 17, 471-495.

Crane, T. (2009). Is perception a propositional attitude? Philosophical Quarterly, 59, 452-469.

Currie, G. (1995). Visual imagery as the simulation of vision. Mind and Language, 10, 25-44.

Currie, G., \& Ian, R. (2002). Recreative minds: Imagination in philosophy and psychology. Oxford: Oxford University Press.

Dennett, D. C. (1996). Seeing is believing: Or is it? In K. Akins (Ed.), Perception (pp. 158-172). Oxford: Oxford University Press.

Findlay, J M., \& Gilchrist, I. D. (2003). Active vision: The psychology of looking and seeing. Oxford: Oxford University Press.

Funkhouser, E. (2006). The determinable-determinate relation. Nous, 40, 548-569.

Gibson, J. J. (1966). The senses considered as perceptul systems. Boston: Houghton Mifflin.

Gibson, J. J. (1979). An ecological approach to visual perception. Boston: Houghton Mifflin.

Gregory, D. (2010). Imagery, the imagination and experience. Philosophical Quarterly, 60, 735-753.

Heckenmueller, E. G. (1965). Stabilization of the retinal image: A review of method, effects and theory. Psychological Bulletin, 63, 157-169.

Hill, C. (1991). Sensations. Cambridge: Cambridge University Press.

Hopkins, R. (2012). What Perky did not show. Analysis, 72, 431-439.

Humphreys, G. W., \& Riddoch, M. J. (2001). Detection by action: Neuropsychological evidence for action-defined templates in search. Nature Neuroscience, 4, 84-88.

Ishiguro, H. (1967). Imagination. Proceedings of the Aristotelian Society Supplementary, 41, 37-56.

Jacob, P. J., \& Jeannerod, M. (2003). Ways of seeing. The scope and limits of visual cognition. Oxford: Oxford University Press. 
Jeannerod, M. (1988). The neural and behavioral organization of goal-directed movements. New York: Oxford University Press.

Jeannerod, M. (1994). The representing brain: Neural correlates of motor intention and imagery. Behavioral and Brain Sciences, 17, 187-245.

Jeannerod, M. (1997). The cognitive neuroscience of action. Oxford: Blackwell.

Johansson, R., Holsanova, J., \& Holmqvist, K. (2006). Pictures and spoken descriptions elicit similar eye movements during mental imagery, both in light and in complete darkness. Cognitive Science, 30, 1053-1079.

Johnston, W. E. (1921). Logic. Part I. Cambridge: Cambridge University Press.

Kelly, S. (2010). The normative nature of perceptual experience. In B. Nanay (Ed.), Perceiving the world. New York: Oxford University Press.

Kind, A. (2001). Putting the image back to imagination. Philosophy and Phenomenological Research, 62, 85-109.

Kleiman, L. (1978). Mental images: Another look. Philosophical Studies, 34, 169-176.

Kosslyn, S. M. (1980). Image and mind. Cambridge, MA: Harvard University Press.

Kosslyn, S. M., Thompson, W. L., \& Ganis, G. (2006). The case for mental imagery. Oxford: Oxford University Press.

Kosslyn, S. M., Thompson, W. L., Kim, I. J., \& Alpert, N. M. (1995). Topographical representations of mental images in primary visual cortex. Nature, 378, 496-498.

Kriegel, U. (2007). The phenomenologically manifest. Phenomenology and the Cognitive Sciences, 6,115-136

Laeng, B., Bloem, I. M., D’Ascenzo, S., \& Tommasi, L. (2014). Scrutinizing visual images: The role of gaze in mental imageyr and memory. Cognition, 131, 263-283.

Laeng, B., \& Teodorescu, D.-S. (2002). Eye scanpaths during visual imagery re-enact those of perception of the same visual scene. Cognitive Science, 26, 207-231.

Lycan, W. (2000). The slighting of smell. In N. Bhushan \& S. Rosenfeld (Eds.), Of minds and molecules: New philosophical perspectives on chemistry (pp. 273-289). Oxford: Oxford University Press.

Mack, A., \& Rock, I. (1998). Inattentional blindness. Cambridge, MA: MIT Press.

Martin, M. G. F. (2002). The transparency of experience. Mind and Language, 17, 376-425.

Mast, F. W., \& Kosslyn, S. M. (2002). Eye movements during visual mental imagery. Trends in Cognitive Science, 6, 271-272.

Matthen, M. (2004). Features, places and things. Philosophical Psychology, 17, 497-519.

Matthen, M. (2010). How things look (and what things look that way). In B. Nanay (Ed.), Perceiving the world. New York: Oxford University Press.

Matthews, G. B. (1969). Mental copies. Philosophical Studies, 78, 53-73.

Nanay, B. (2009). Imagining, recognizing and discriminating. Reconsidering the ability hypothesis. Philosophy and Phenomenological Research, 79, 699-717.

Nanay, B. (2010a). Attention and perceptual content. Analysis, 70, 263-270.

Nanay, B. (2010b). Perception and imagination: Amodal perception as mental imagery. Philosophical Studies, 150, 239-254.

Nanay, B. (2011a). Do we see apples as edible? Pacific Philosophical Quarterly, 92, 305-322.

Nanay, B. (2011b). Do we sense modalities with our sense modalities? Ratio, 24, 299-310.

Nanay, B. (2011c). Ambiguous figures, attention and perceptual content. Phenomenology and the Cognitive Sciences, 10, 557-561.

Nanay, B. (2012a). Action-oriented perception. European Journal of Philosophy, 20, 430-446.

Nanay, B. (2012b). The philosophical implications of the Perky experiments. Analysis, 72, 439-443.

Nanay, B. (2012c). Perceiving tropes. Erkenntnis, 77, 1-14.

Nanay, B. (2013). Between perception and action. Oxford: Oxford University Press.

Nanay, B. (2012d). Perceptual phenomenology. Philosophical Perspectives, 26, 235-246.

Neiworth, J. J. (1992). Cognitive aspects of movement estimation: A test of imagery in animals. In K. W. Honig \& J. G. Fetterman (Eds.), Cognitive aspects of stimulus control (pp. 323-346). Hillsdale, NJ: Lawrence Erlbaum Associates.

Noordhof, P. (2002). Imagining objects and imagining experiences. Mind and Language, 17, 426-455.

O'Callaghan, C. (2007). Sounds. Oxford: Oxford University Press.

Oakley, D. A. (1985). Cognition and imagery in animals. In D. A. Oakley (Ed.), Brain and Mind (pp. 99-131). London: Methuen.

Page, J. W., Duhamel, P., \& Crognale, M. A. (2011). ERP evidence of visualization at early stages of visual processing. Brain and Cognition, 75(2), 141-146. 
Peacocke, C. (1985). Imagination, experience, and possibility: A Berkeley-an view defended. In J. Foster \& H. Robinson (Eds.), Essays on Berkeley. (pp. 19-35). Oxford: Clarendon.

Peacocke, C. (1992). A study of concepts. Cambridge, MA: The MIT Press.

Penn, D. C., \& Povinelli, D. J. (2007). On the lack of evidence that non-human animals possess anything remotely resembling a 'theory of mind'. Philosophical Transactions of the Royal Society B, 362, 731-744.

Perky, C. W. (1910). An experimental study of imagination. American Journal of Psychology, 21, 422-452.

Posner, M. I. (1980). Orienting of attention. Quaterly Journal of Experimental Psychology, 32, 2-25.

Posner, M. I. (1984). Current research in the study of selective attention. In E. Donchin (Ed.), Cognitive psychophysiology: Event related potentials and the study of cognition. Hillsdale, NJ: Erlbaum.

Posner, M. I., Walker, J. A., Friedrich, F. J., \& Rafal, R. D. (1984). Effects of parietal injury on covert orienting of attention. Journal of Neuroscience, 4, 1863-1874.

Prinz, J. (2010). How do perceptual states become conscious? In B. Nanay (Ed.), Perceiving the world. New essays on perception. New York: Oxford University Press.

Pylyshyn, Z. W. (2007). Things and places: How the mind connects with the world. Cambridge, MA: MIT Press.

Richardson, A. (1969). Mental imagery. New York: Springer Publishing Company Inc.

Riddoch, M. J., Edwards, M. G., \& Humphreys, G. W. (1998). Visual affordances direct action: Neuropsychological evidence from manual interference. Cognitive Neuropsychology, 15, 645-693.

Rilling, M. E., \& Neiworth, J. J. (1987). Theoretical and methodological considerations for the study of imagery in animals. Learning and Motivation, 18, 57-79.

Ryle, G. (1949). The concept of mind. London: Huchinson.

Schellenberg, S. (2013). Belief and desire in imagination and immersion. Journal of Philosophy, 110, 497-517.

Scholl, B. J., \& Tremoulet, P. D. (2000). Perceptual causality and animacy. Trends in Cognitive Sciences, 4, 299-309.

Segal, S. J. (1972). Assimilation of a stimulus in the construction of an image: The Perky effect revisited. In W. P. Sheehan (Ed.), The function and nature of imagery (pp. 203-230). New York: Academic Press.

Segal, S. J., \& Nathan, S. (1964). The Perky effect: Incorporation of an external stimulus into an imagery experience under placebo and control conditions. Perceptual and Motor Skills, 19, 385-395.

Shorter, J. M. (1952). Imagination. Mind, 61, 528-542.

Siegel, S. (2005). The phenomenology of efficacy. Philosophical Topics, 33, 65-84.

Siegel, S. (2006). Which properties are represented in perception? In T. Gendler \& J. Hawthorne (Eds.), Perceptual experience (pp. 481-503). Oxford: Oxford University Press.

Siegel, S. (2009). The visual experience of causation. Philosophical Quarterly, 59, 519-540.

Simons, D. J., \& Chabris, C. F. (1999). Gorillas in our midst: Sustained inattentional blindness for dynamic events. Perception, 28, 1059-1074.

Smith, J. (2006). Bodily awareness, imagination and the self. European Journal of Philosophy, 14, 49-68.

Spivey, M., \& Geng, J. (2001). Oculomotor mechanisms activated by imagery and memory: Eye movements to absent objects. Psychological Research, 65, 235-241.

Stazicker, J. (2011). Attention, visual consciousness and indeterminacy. Mind and Language, 26, 156-184.

Tomasello, M., Call, J., \& Hare, B. (2003). Chimpanzees understand psychological states-The question is which ones and to what extent. Trends in Cognitive Science, 7, 153-156.

Trehub, A. (1991). The cognitive brain. Cambridge, MA: MIT Press.

Van Leeuwen, N. (2011). Imagination is where the action is. Journal of Philosophy, 108, 55-77.

Wolfe, J. M. (1999). Inattentional amnesia. In V. Coltheart (Ed.), Fleeting memories. Cognition of brief visual stimuli (pp. 71-94). Cambidge, MA: MIT Press.

Yeshurun, Y., \& Carrasco, M. (1998). Attention improves or impairs visual performance by enhancing spatial resolution. Nature, 396, 72-75. 